\title{
Inferred pore pressures at the Costa Rica subduction zone: implications for dewatering processes
}

\author{
Demian M. Saffer ${ }^{\mathrm{a}, *}$, Eli A. Silver ${ }^{\mathrm{a}}$, Andrew T. Fisher ${ }^{\mathrm{a}, \mathrm{b}}$, Harold Tobin ${ }^{\mathrm{c}}$, \\ Kate Moran ${ }^{\mathrm{d}}$ \\ a Institute of Tectonics, University of California, Santa Cruz, CA 95064, USA \\ b Department of Earth Sciences, University of California, Santa Cruz, CA 95064, USA \\ c Department of Earth and Environmental Science, New Mexico Institute of Technology, Socorro, NM, USA \\ d Bedford Institute of Oceanography, Dartmouth, NS, Canada
}

Received 20 May 1999; accepted 8 February 2000

\begin{abstract}
Drilling on Ocean Drilling Program (ODP) Leg 170, offshore Costa Rica indicates that the entire incoming sedimentary section is underthrust. Thus, observed changes in the thickness of underthrust sediments as they are progressively buried beneath the margin wedge provide a direct measure of the rate and magnitude of sediment dewatering. Laboratory consolidation tests indicate that in situ excess pore-fluid pressures within the underthrust section range from 1.3 MPa at the top of the section to 3.1 MPa near the base. The inferred pore pressure profile implies that fluids escape the uppermost sediments most rapidly, whereas the basal sediments remain essentially undrained. This interpretation suggests that the sedimentary and underlying ocean crustal hydrologic systems are decoupled. We use a simple model of fluid flow to demonstrate that dewatering of the underthrust sediments can occur via lateral flow only if sediment permeability is strongly anisotropic, or if flow is focused along permeable stratigraphic layers. If significant dewatering occurs by vertical fluid flow, it must occur within closely spaced, high-permeability conduits. (C) 2000 Elsevier Science B.V. All rights reserved.
\end{abstract}

Keywords: pore pressure; consolidation; marine sediments; subduction zones; numerical models; experimental studies

\section{Introduction}

Fluids play an important role in deformation and mass transfer in the Earth's crust. Pore-fluid pressure is intimately linked to the mechanics and morphology of accretionary wedges and thrust

\footnotetext{
* Corresponding author. Tel.: +1-831-459-2762;

Fax: +1-831-459-3074; E-mail: dsaffer@es.ucsc.edu
}

belts (e.g. [1,2]). The fluid content of porous material influences deformation style and strength and may control the updip limit of the seismogenic zone (e.g. [3]) and earthquake rupture processes (e.g. [4]). Fluids in subduction zones are also important for transporting heat and dissolved chemical species. Evidence from theoretical studies, cosmogenic radionuclides incorporated in arc magmas and trace element composition of volcanics show that sediments can subduct to depths of $100-200 \mathrm{~km}[5,6]$. The properties of under- 


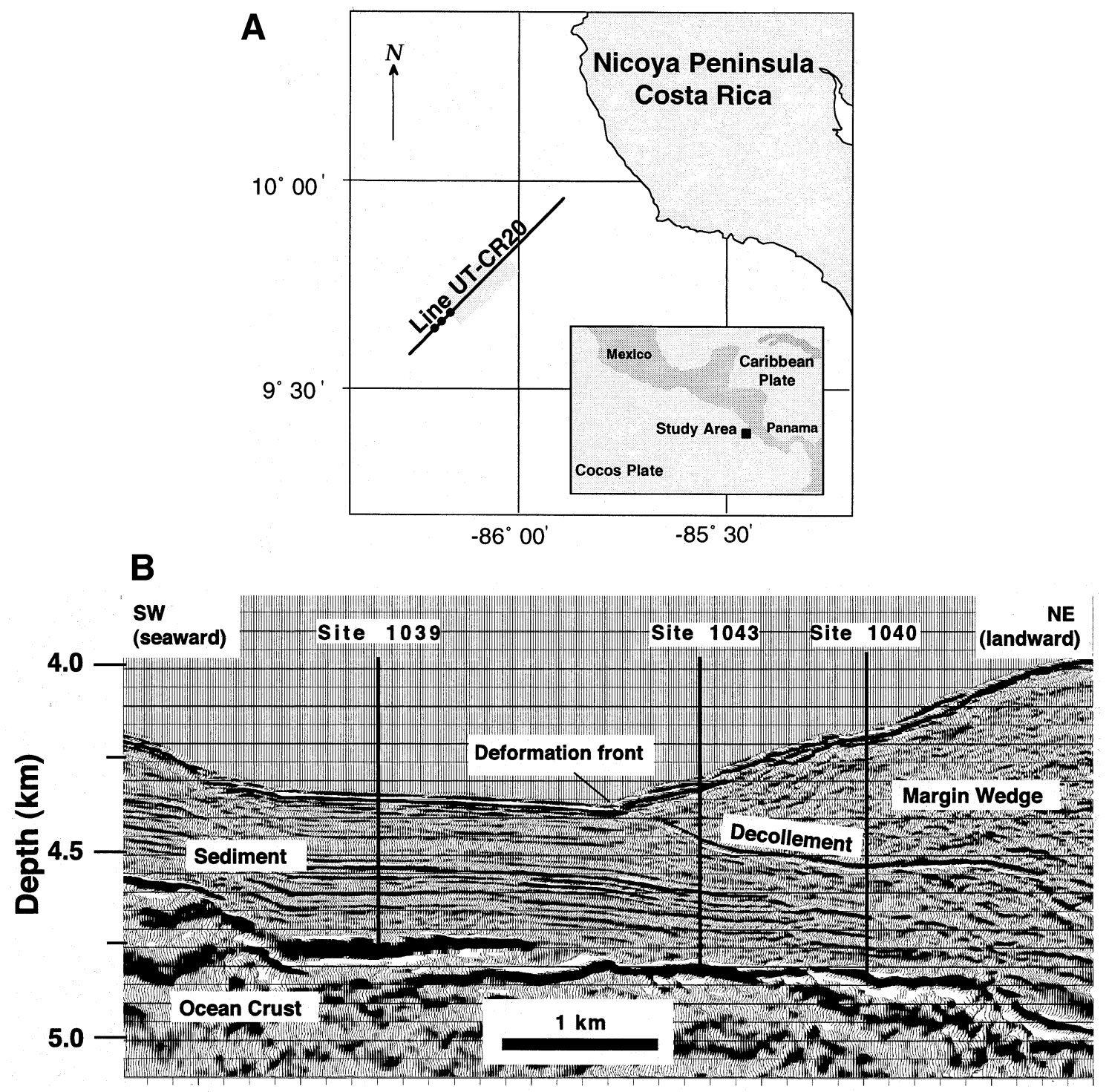

Fig. 1. (A) Map of study area showing location of 3D seismic data set (gray box), line UT-CR20 and Sites 1039, 1040, and 1043 (black dots). (B) Seismic cross-section along UT-CR 20, showing location of ODP Sites 1039, 1040 and 1043.

thrust sediments and, in particular the amount of water carried with them, are important for understanding material properties in the seismogenic zone, growth and deformation of sedimentary prisms, the effects of shallow fluid expulsion on composition of subducted sediment and the contribution of fluid expulsion to seawater chemistry for selected elements.

Ocean Drilling Program (ODP) Leg 170 fo- cused on the Middle America Trench, formed by the eastward subduction of the Cocos Plate beneath the Caribbean Plate offshore Costa Rica at $\sim 85 \mathrm{~km} / \mathrm{Myr}$ (Fig. 1A). Analysis of seismic reflection profiles and gamma ray logs suggests that the present margin is non-accretionary, in that less than $5 \mathrm{~m}$ of sediment are offscraped at the toe [7]. Chrono-stratigraphic studies, which indicate nearly identical age-depth relationships 


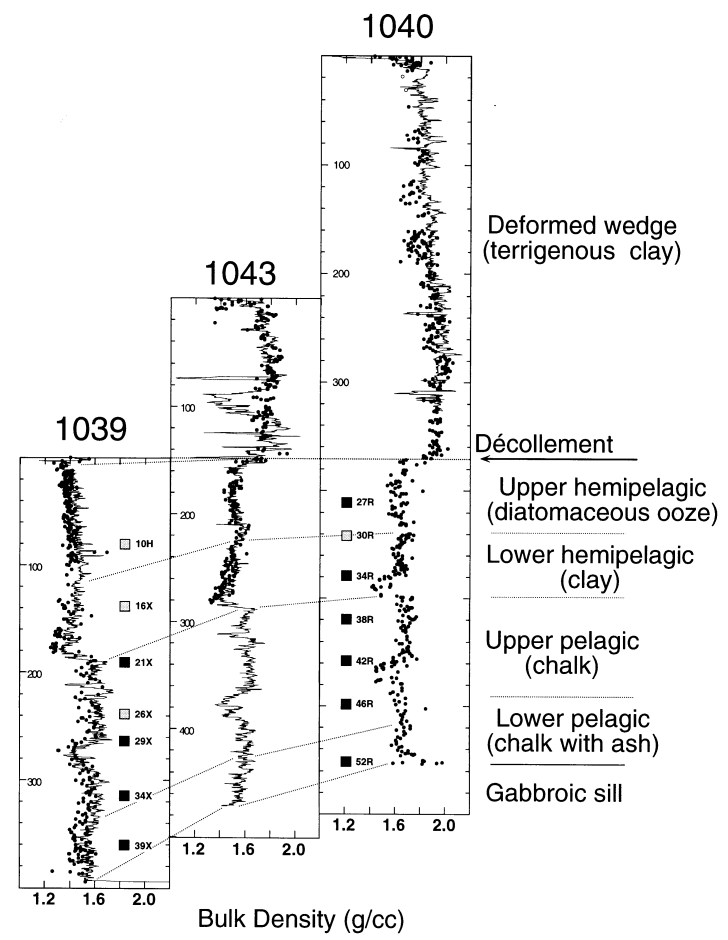

Fig. 2. Logged bulk density showing thinning of the hemipelagic and pelagic units between Sites 1039 and 1040. Black line represents logging while drilling data (LWD); data points are shipboard measurements. Filled boxes denote locations and numbers of our samples from Sites 1039 and 1040. Black boxes represent samples for consolidation tests only; gray boxes denote samples for both permeability and consolidation tests.

for the incoming and subducted sedimentary sequences, confirm the lack of accretion. The nature of the thick margin wedge is undetermined; it is interpreted as either an accretionary wedge [8] or a continuation of the onshore Nicoya complex overlain by several hundred meters of slope apron sediments [7,9]. The hydrologic contribution of underthrust sediments is accentuated in non-accretionary systems like the Costa Rican subduction zone, because high porosity surface sediment is subducted rather than incorporated into an accretionary wedge (e.g. [10]).

At the Costa Rican margin, drilling results and seismic reflection surveys provide accurate constraints on the thinning of the underthrust sedimentary section as it is progressively buried. Because virtually no sediment is offscraped, the observed thinning of units is due to water loss and densification and thus provides a quantitative indication of expelled water volume. Solutionmass transfer may account for a portion of the thickness change in some parts of the underthrust sequence; however, the loss of solid material by this mechanism requires accompanying fluid expulsion through the sediments to carry dissolved material. Furthermore, the observed decrease in void ratio with progressive burial reflects only fluid loss by dewatering. At reference Site 1039, located $1.5 \mathrm{~km}$ seaward of the trench near the Nicoya Peninsula (Fig. 1B), the incoming sedimentary sequence is about $380 \mathrm{~m}$ thick and consists of $\sim 160 \mathrm{~m}$ of siliceous hemipelagic sediments overlying $\sim 220 \mathrm{~m}$ of pelagic carbonates (Fig. 2). The upper, hemipelagic section consists of interbedded diatomaceous ooze and thin (5-14 $\mathrm{cm}$ ) ash layers and pods which grade upward from sand-sized clasts above sharp basal contacts into the diatomaceous ooze [7]. The pelagic section is characterized by a sharp increase in biogenic material, dominantly siliceous and calcareous oozes. Ash layers are rare within the pelagic section. This general stratigraphy is regionally continuous, as indicated by drilling on DSDP Legs 67 and 84 offshore Guatemala [11,12]. Site 1040, located $1.6 \mathrm{~km}$ landward of the trench, penetrated through the décollement and entire underthrust sequence to a total depth of 653 mbsf. Some deformation is evident in the underthrust sediments at Site 1040, where dipping beds occur locally in the hemipelagic sequence. In the interval between 423-480 mbsf, maximum bedding dips approach $45^{\circ}$ and some microfaults are evident [7]. Correlation of borehole density logs from Sites 1039, 1043 (0.5 km landward of the trench) and 1040 show that the upper, hemipelagic unit is $67 \%$ of its original thickness by Site 1040 and the lower pelagic unit is $\sim 80 \%$ of its original thickness (Fig. 2). We calculate that $\sim 8$ $\mathrm{m}^{3} \mathrm{yr}^{-1}$ of fluids are expelled per meter of margin from underthrust sediments between the time they are first subducted and when they reach $1.6 \mathrm{~km}$ arcward. Of this, $5.4 \mathrm{~m}^{3} \mathrm{yr}^{-1}$ are lost by the hemipelagic section. We estimate that the total fluid volume expelled between the trench and Site 1040 represents $\sim 35 \%$ of the pore water con- 
tained in the entire sediment column, and that the fluids expelled from the hemipelagic section are $\sim 46 \%$ of the available pore water in these sediments. Thinning of the pelagic unit is poorly constrained due to uncertainty in correlating the base of the section, but negligible changes in void ratio between Sites 1039 and 1040 suggest minimal densification. In this study, we focus on dewatering of the hemipelagic sediment section, because its thinning and densification are well constrained. The goals of our study are to: (1) estimate in situ pore pressures in underthrust sediments from laboratory consolidation tests, (2) estimate in situ permeabilities from laboratory tests and (3) assess the implications of these data for dewatering of the underthrust sediments.

\section{Consolidation and permeability measurements}

In order to determine consolidation indices and permeabilities for the full range of porosities present in the study area, we ran uniaxial consolidation tests at effective stresses up to $6 \mathrm{MPa}$. This corresponds to a burial depth of $\sim 780 \mathrm{~m}$ under conditions of hydrostatic fluid pressure. For higher in situ fluid pressures, these measurements correspond to greater burial depths. We obtained $15 \mathrm{~cm}$ long whole round core samples from Sites 1039 and 1040 for consolidation and permeability tests. We used CT scans of the whole round core samples to select undisturbed portions of the core for our experiments. We performed our tests on samples measuring $6.25 \mathrm{~cm}$ in diameter and 1.5-1.6 cm in initial length.

The response of sediment to an applied load depends upon the consolidation history of the sample. Upon reconsolidation in the laboratory, a sample deforms along an elastic rebound curve until reaching loads exceeding its maximum past burial stress $\left(\mathrm{Pc}^{\prime}\right)$, assuming that the sample has not been disturbed or reworked [13]. At stresses beyond $\mathrm{Pc}^{\prime}$, the sample deforms plastically and the strain response for a given stress increment changes. We determined $\mathrm{Pc}^{\prime}$ from laboratory tests following the Casagrande method (Fig. 3) [13] (all consolidation test data are available on the internet at http://emerald.ucsc.edu/ afisher).
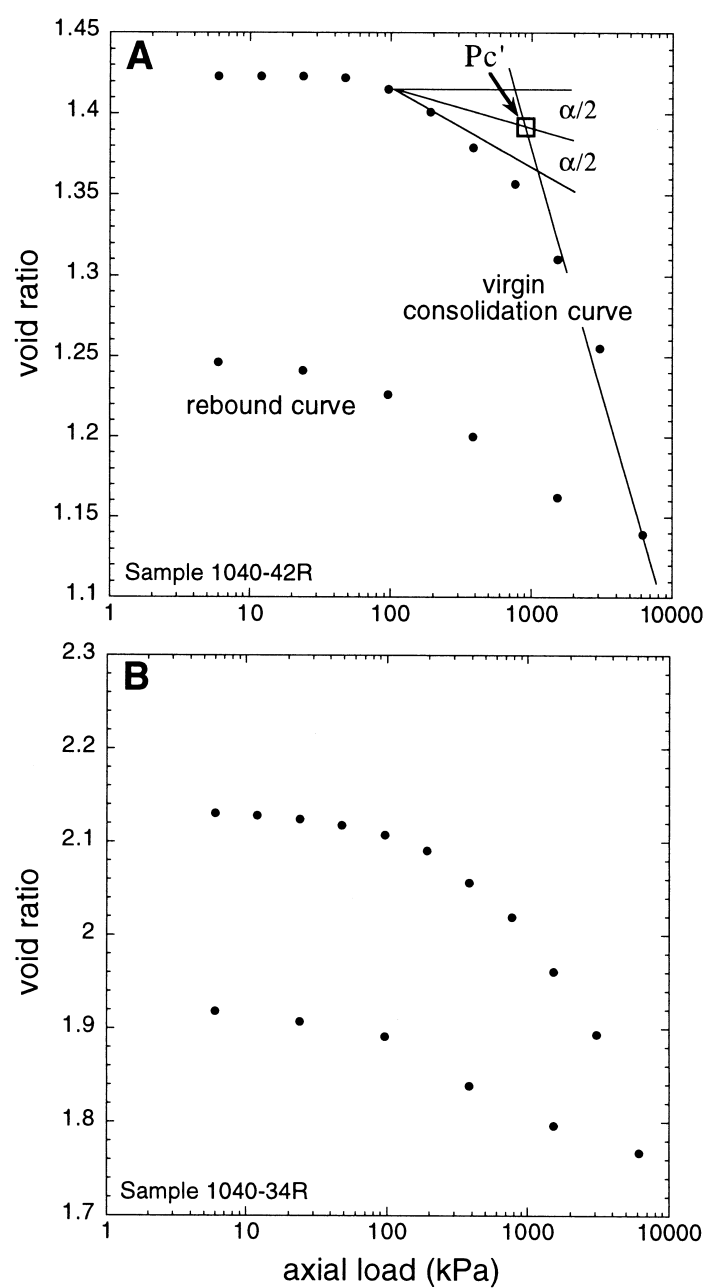

Fig. 3. (A) Consolidation test result for sample 1040-42R, from the pelagic section (Fig. 2). (B) Consolidation test result for sample 1040-34R, from the hemipelagic section (Fig. 2). In situ effective stress, assumed equal to the maximum past burial stress, $\mathrm{Pc}^{\prime}$ (see Section 6), is determined by the Casagrande construction (e.g. [13]). Using the Casagrande method, a line is drawn tangent to the consolidation curve at its point of maximum curvature. The intersection of the virgin consolidation curve and a line which bisects the angle $(\alpha)$ between the tangent line and a line of constant void ratio yields an estimate of Pc. Conservative estimates of minimum and maximum possible $\mathrm{Pc}$ values are effective stresses at which sample void ratio during the consolidation test no longer plots on a rebound curve (minimum) or virgin consolidation curve (maximum) (e.g. [13]).

For the case of minimally deformed underthrust sediments (e.g. [14,15]), the maximum past effective stress can be interpreted as the in situ effective stress. Combined with down-hole 
measurements of bulk density, which, when integrated over depth, provide a calculation of the total overburden stress, the measurement of $\mathrm{Pc}^{\prime}$ in core samples can be used to infer pore fluid pressures by:

$\mathrm{Pf}=\sigma_{\text {overburden }}-\mathrm{Pc}^{\prime}$

The tilted beds and microfaulting observed in portions of the underthrust sequence at Site 1040 imply that the consolidation of underthrust units is more complex than laterally confined uniaxial compression, and may include a contribution of lateral shortening related to tectonic stresses. However, the applicability of one-dimensional loading in the shallow subduction environment is justified by several lines of evidence. First, $\mathrm{Pc}^{\prime}$ values from the upper $180 \mathrm{~m}$ of hemipelagic sediment at the reference site indicate that they are normally consolidated [16]. This implies that the reference site does not 'feel' lateral stresses generated by the topographic load of the nearby wedge and that underthrust sediments are not efficient at transmitting stresses laterally. Second, anisotropy of magnetic susceptibility (AMS) data document that the maximum principal strain in underthrust sediments is essentially vertical, both at Costa Rica (Housen, 1999, personal communication) and at other subduction zones [17,18]. Third, settlement calculated from laboratory-derived consolidation coefficients and estimated in situ effective stresses indicate that one-dimensional strain can explain, to a first order approximation, the thinning of sedimentary units seen between Site 1039 and 1040 [16].

We conducted constant flow-rate permeability tests for samples from the reference site at several stages during sample consolidation, in order to establish a systematic relationship between void ratio and intrinsic permeability (e.g. [19]). We ran six flow tests at each of several void ratios for samples from the hemipelagic section. Permeability is calculated from each test by Darcy's law:

$$
K=\frac{Q}{A \times \frac{\mathrm{d} h}{\mathrm{~d} l}}
$$

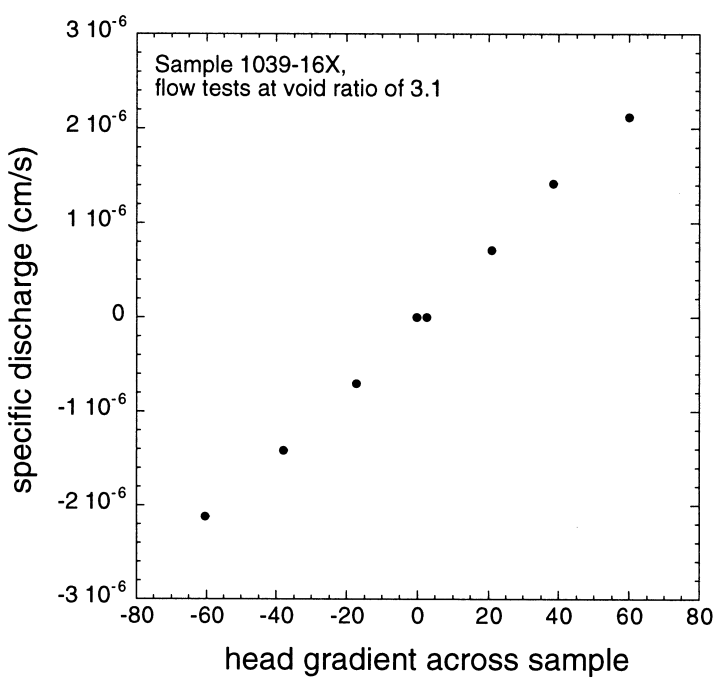

Fig. 4. Specific discharge versus head gradient for sample 1039-16X, at a void ratio of 3.1. We measured the steadystate pressure difference across the sample (plotted here as head gradient) at seven discharge rates. Sample permeability is defined by the slope of the best-fit line to these measurements.

where $K$ is hydraulic conductivity $\left(\mathrm{L} \mathrm{T}^{-1}\right)$, which is directly related to permeability, $Q$ is volume flux $\left(\mathrm{L}^{3} \mathrm{~T}^{-1}\right.$, controlled by a high precision flow pump), $A$ is the cross-sectional area of the sample and $\mathrm{d} h / \mathrm{d} l$ is the head gradient (dimensionless) calculated from the measured pressure difference across the sample, the sample height and seawater density. In our experimental apparatus, water enters either the top or base of the sample; thus our measurements represent vertical sample permeability. Multiple flow tests at a given void ratio allow assessment of experimental error (Fig. 4), whereas permeability tests at several void ratios yield a systematic log-linear relationship between intrinsic permeability and void ratio (e.g. [19]).

\section{Experimental results}

Pore-fluid pressures determined using Eq. 1 for Site 1040 are highest at the base of the underthrust sequence, generally decreasing upward (Fig. 5). Inferred excess pore pressures (given as 


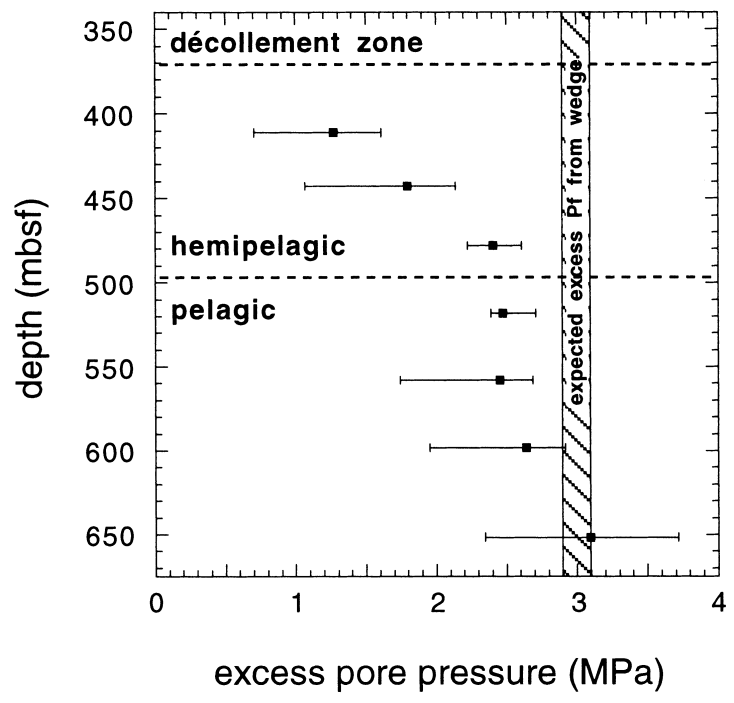

Fig. 5. Excess pore pressures at Site 1040, inferred from consolidation tests. Error bars are conservative estimates from individual consolidation tests (see explanation in Fig. 3). Striped region indicates excess pore fluid pressures expected from undrained loading beneath the wedge at Site 1040, based on bulk density of overlying sediments.

pressure above hydrostatic) range from 2.4-3.1 $\mathrm{MPa}$ in the pelagic sequence and from 1.3-2.4 $\mathrm{MPa}$ in the hemipelagic sequence. These pore pressures correspond to consolidation ratios of $0.34-0.40$ and $0.33-0.60$, respectively. If underthrust sediments are undrained, the expected excess fluid pressure at Site 1040 due to burial below the wedge is $3.0 \pm 0.1 \mathrm{MPa}$, calculated from bulk density logs and thickness of the overlying wedge. We consider this value as an upper limit, because: (1) the increase in pore pressure due to rapid burial cannot exceed the weight of overlying material and (2) underthrust sediments are partially drained, as shown by observed decreases in void ratio and thickness (Fig. 2).

Cementation should make samples appear overconsolidated, yielding overestimates of $\mathrm{Pc}^{\prime}$ and underestimating in situ pore pressure. For this reason, our estimates of excess pore pressure should be viewed as minima, particularly in the pelagic carbonate where cementation is most likely. However, the observation that estimated in situ pore pressures at the base of the pelagic carbonates are close to the upper limit described above (Fig. 5) suggests that the influence of cementation on consolidation history is insignificant.

Our permeability measurements show a systematic decrease in permeability with decreasing void ratio (Fig. 6). For samples from the hemipelagic section, the data suggest a relationship between permeability and void ratio of the form:

$\log k=-18.75+0.90 e$

where $k$ is permeability in $\mathrm{m}^{2}$, and $e$ is void ratio. Although there is scatter in the data, all measured permeability values for the hemipelagic section lie within one order of magnitude of the relation described by Eq. 3. Our data for samples from the hemipelagic sequence are consistent with those of Bolton et al. [20], who report permeabilities of $10^{-16}$ to $\sim 2 \times 10^{-18} \mathrm{~m}^{2}$ at a range of mean stress-

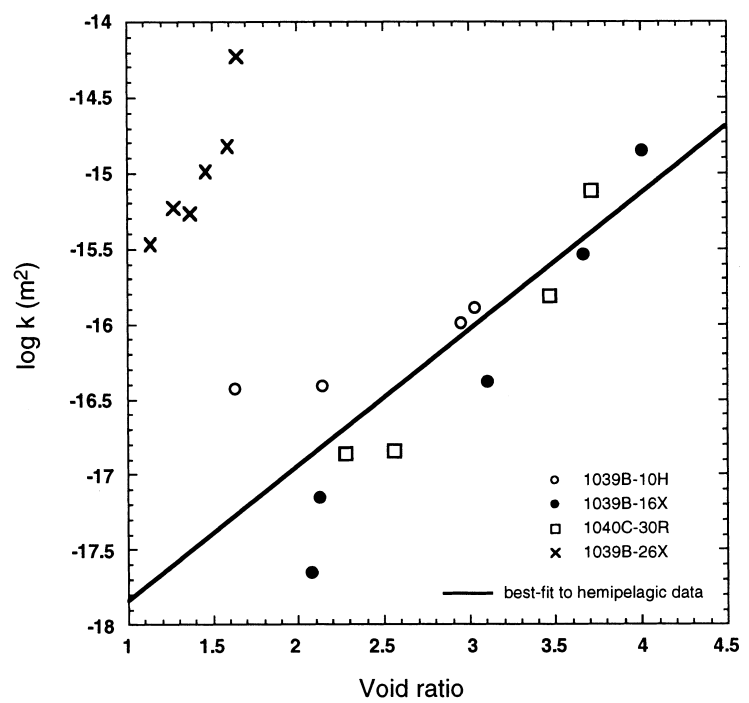

Fig. 6. Log permeability versus void ratio for samples 1039B-10H, 1039B-16X and 1040C-30R (hemipelagic section) and sample 1039B-26X (pelagic section). Symbols are permeability values determined from multiple constant flow rate tests at each void ratio. Standard deviation for measurements at each void ratio are smaller than the data points. Data show a permeability decrease of $\sim 2$ orders of magnitude in the hemipelagic sediments as void ratio decreases from 4.0 to 2.0 (porosity reduction from 80 to $66 \%$ ). Permeability in the pelagic carbonate is $\sim 2$ orders of magnitude higher than that for hemipelagic sediments at the same void ratio. 
es between $0.2-1.2 \mathrm{MPa}$. The permeability-void ratio relationship defined by these data is typical of both fine-grained marine sediments (e.g. [21]) and of compilations of permeability-porosity relationships for argillaceous rocks [19]. Our measured permeabilities for the pelagic carbonate-rich section are consistently $\sim 2$ orders of magnitude higher than those we report for the hemipelagic section (Fig. 6), also consistent with the results of Bolton et al. [20].

\section{Hydrologic implications}

Inferred excess pore pressures at Site 1040 are highest at the base of the underthrust sequence, and decrease upward (Fig. 5). Inferred pore pressures at the base of the sequence are approximately equal to the increase in overburden expected for loading beneath the present deformed wedge, suggesting that the basal sediments are essentially undrained in response to tectonically induced burial. Decreasing consolidation with depth suggests that higher relative permeability allows more rapid fluid escape from the hemipelagic sediments. This interpretation is consistent with the small amount of thinning observed in the pelagic units and the rapid thinning of the hemipelagic sequence as it is progressively buried (Fig. 2). The observed consolidation pattern could result from higher lateral bulk permeability in the hemipelagic section, or increased proximity to a subhorizontal drainage surface. Potential horizontal conduits include the décollement, deformed sediments in the upper hemipelagic sequence identified with anomalously high bedding dips [7] or high-permeability stratigraphic horizons. Thin (5$14 \mathrm{~cm}$ ), coarse-grained ash layers with potentially high permeability are candidates for stratigraphic flow conduits distributed within the hemipelagic sequence [7].

Pore-water chlorinity profiles indicate that flow in the underthrust sediments is decoupled from flow within the high-permeability décollement [7]. This is consistent with the presence of a $\sim 10 \mathrm{~m}$ thick ductile zone just below the hydrologically active décollement, which probably acts as a low-permeability flow barrier [22]. Geochem- ical profiles at Sites 1039, 1043 and 1040 show no evidence for significant vertical fluid flow in the underthrust section [7]. In addition, the presence of low-permeability layers (resulting from either compaction or lithologic variation) will significantly decrease bulk vertical conductivity. Based on these considerations, we suggest that over the seaward $\sim 1.6 \mathrm{~km}$ of the subduction zone, fluid escape along stratigraphic horizons is more important than vertical flow upward to a high-permeability décollement or to a conduit just below it (as would be the case for fully one-dimensional consolidation with a high-permeability drain at the top of the underthrust sequence).

The pore pressure profile for Site 1040, along with the minimal thinning of pelagic units, suggests that the ocean crust does not act as a significant sediment dewatering pathway for the overlying sedimentary section. In contrast, depressed regional heat flow over much of the equatorial Pacific provides evidence that significant lateral fluid flow occurs within the oceanic crust of the Cocos plate (e.g. [23]). Active flow of seawater in the ocean crust at Sites 1039 and 1040 is suggested by pore water $\mathrm{Mg}$ and $\mathrm{Ca}$ concentrations, which approach seawater values near the base of the sediment column [7,24]. Arrested consolidation of pelagic sediments in the underthrust sequence at Costa Rica may be reconciled with measured high permeabilities in ocean crust (e.g. [25]) and evidence of vigorous fluid flow in the Cocos crust (1) if the sediment and crustal hydrologic systems are separated by a low-permeability barrier or (2) if the two flow systems are effectively isolated by high fluid pressures in the crust, which prevent downward flow of fluids. At the base of both Sites 1039 and 1040, drilling encountered a series of $\sim 3-9 \mathrm{~m}$ thick gabbroic sills which, if regionally continuous, may represent barriers to vertical fluid flow.

Measured permeability values for pelagic carbonate samples, both from this study and reported by Bolton et al. [20], are significantly higher than those reported for the hemipelagic sequence. The higher observed permeability within the pelagic sequence suggests that these sediments should be better drained than the overlying hemipelagic section. This inference is difficult to 
reconcile with pore pressures inferred from consolidation tests, because the pelagic sediments appear less well drained than the overlying hemipelagic sequence. However, void ratios within the pelagic sequence do not decrease significantly between Sites 1039 and 1040 (Fig. 2) and our estimates of maximum past burial stress suggest that these sediments are essentially undrained. If the pelagic sediments act as an efficient dewatering pathway, we would expect to see a decrease in both void ratio and inferred excess pore pressure for sediments at the base of the hemipelagic sediment sequence as a result of proximity to a highpermeability layer. These changes are not observed in the density logs (Fig. 2) or the inferred excess pore pressure profile at Site 1040 (Fig. 5). If the pelagic carbonates maintain a permeability significantly higher than the overlying hemipelagic section, fluids derived from greater depths may flow preferentially within the pelagic section; hydrologic communication with these deep, higher pressure fluids would result in elevated pore pressures at shallow depths (e.g. [14]). Ultimately, this question cannot be resolved without additional permeability measurements or in situ pore pressure measurements. Due to the uncertainty in both thickness changes and permeability for the pelagic section, we focus primarily on dewatering of the hemipelagic sediments in the following analyses.

\section{Simple hydrologic models}

\subsection{Model description}

Here, we evaluate the permeability conditions necessary for dewatering by lateral flow within the hemipelagic sediments. We consider a simple one-dimensional, steady-state model of fluid flow in the hemipelagic section, extending from the toe of the wedge to $2 \mathrm{~km}$ landward (Fig. 7A). Thinning of stratigraphic units beneath the sedimentary wedge provides a measure of the fluid volume produced by compaction within the model domain. Fluids derived from dewatering of deeper underthrust sediments enter the model domain at the arcward boundary. Any realistic configuration of drainage pathways must accommodate the known compaction-driven fluid sources and yield pressures comparable to those inferred from consolidation tests. The expected excess fluid pressure under undrained conditions due to burial below the wedge represents an upper limit on modeled pressures.

One-dimensional steady-state fluid flow is described by:

$\frac{\partial^{2} h(x)}{\partial x^{2}}=\frac{-w(x) b(x)}{T(x)}$

where $h$ is hydraulic head, $x$ is distance landward from the toe of the sediment wedge, $w$ represents fluid sources in units of $\mathrm{v} / \mathrm{v} \mathrm{s}^{-1}, b$ is aquifer thickness and $T$ is aquifer transmissivity, the product of thickness and hydraulic conductivity. Aquifer thickness is constrained by drilling at Sites 1039, 1040 and 1039 (Fig. 7B). Fluid sources are given by:

$\frac{-\partial[b(x)]}{\partial x} \frac{V_{\mathrm{p}}}{b(x)}$

where $V_{\mathrm{p}}$ is the plate velocity. Fluid sources decrease with arcward distance, because the thinning rate of the underthrust decreases with progressive burial. Compaction-driven fluid sources are largest near the toe of the wedge and drop by over an order of magnitude by $\sim 250 \mathrm{~m}$ arcward (Fig. 7B). The use of a one-dimensional hydrologic model implicitly assumes a uniform distribution of fluid sources with depth. In reality, fluid sources are highest at the top of the underthrust sequence and decrease downward. We evaluate the sensitivity of modeled pore pressures to uncertainty in fluid source distribution by testing two scenarios: one in which sources are assumed to follow a smooth function fit to observed aquifer thickness variations, based on Eq. 5 and one in which we assume constant sources throughout the hemipelagic section (Fig. 7B).

Aquifer transmissivity varies with position because the underthrust units thin and their permeability decreases with decreasing void ratio (Fig. 7C). We first evaluate simple constant permeability models, in order to estimate the conditions 


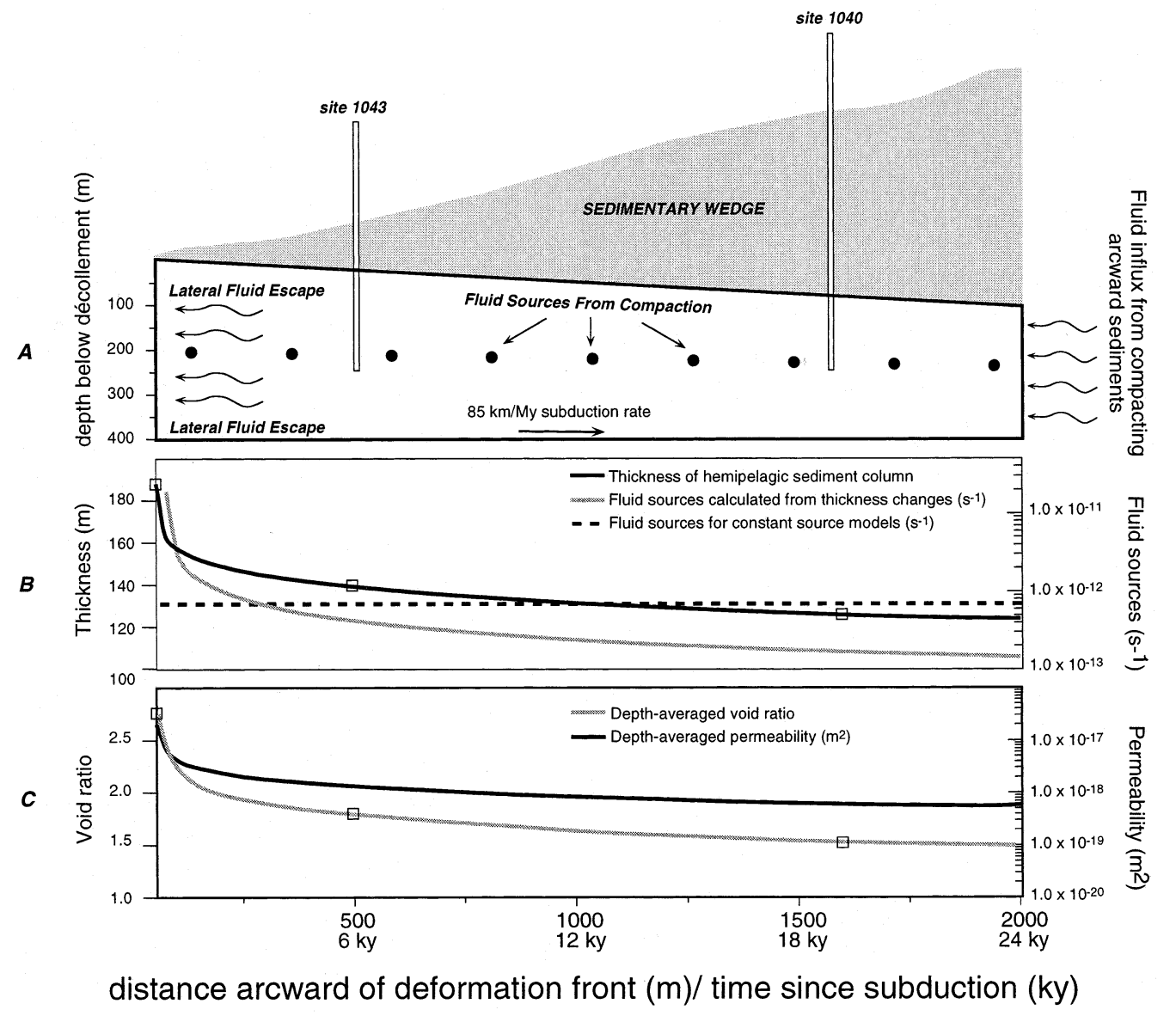

Fig. 7. (A) Schematic diagram of hydrologic model domain. Fluid sources, depicted as black dots, result from compaction of underthrust sediments. Additional influx of fluids at the landward boundary, derived from deeper sediments, must also be expelled at the toe of the wedge. We assume steady-state conditions, where the thickness and porosity distribution remain constant through time, relative to the tip of the overlying wedge. (B) Plot of hemipelagic unit thickness (solid black line), fluid sources calculated from observed thinning (solid gray line) and fluid sources for constant source models (dashed black line) versus distance landward of the sedimentary wedge toe. Open boxes represent data points. Solid black line shows a power-law curve fit to the hemipelagic thickness data. Sources are given in volume of water per total volume per second. (C) Plot of mean void ratio (data) and permeability (calculated from Eq. 3) in the hemipelagic section versus distance landward of the sedimentary wedge toe.

required for dewatering. We then evaluate variable permeability models, where permeability is calculated from mean void ratio using our laboratory-determined permeability-void ratio relations (Eq. 3).

We solve Eq. 4 for the steady-state head distribution by integration. We assign a hydrostatic Dirichlet (constant head) boundary condition to the sediment column at the toe of the deformed wedge. The landward boundary is a Neumann (fixed head gradient or constant flux) boundary with a head gradient assigned using Darcy's law, assuming a flux across the boundary generated by compaction of deeper underthrust sediments. Fluids crossing this boundary may be derived from compaction, mineral dehydration reactions, and thermogenic hydrocarbon generation. We evaluate the sensitivity of modeled pore pressures to the amount of fluid influx from deeper sediments by considering cases where fluid influx is 0,50 and $100 \%$ of the remaining interstitial water at Site 1040. The case of $0 \%$ fluid influx represents an 
absolute minimum, and implies that all fluids expelled from deeper underthrust sediments escape by vertical flow. Although an influx equal to $100 \%$ of remaining pore water is not an absolute maximum (because of unknown deep fluid sources), we consider it unlikely (1) that sediment porosity is reduced to $0 \%$ and (2) that all fluids derived from underthrust sediments at depth escape solely by lateral flow. Furthermore, deeper underplating would disturb the lateral continuity of underthrust sediments as they are cut by faults and incorporated into the overlying wedge [26]. For these reasons, we consider an influx equal to $100 \%$ of remaining pore water to be a likely upper limit.

\subsection{Constant permeability model results}

Constant permeability models indicate that for dewatering by lateral flow, the bulk sediment per-

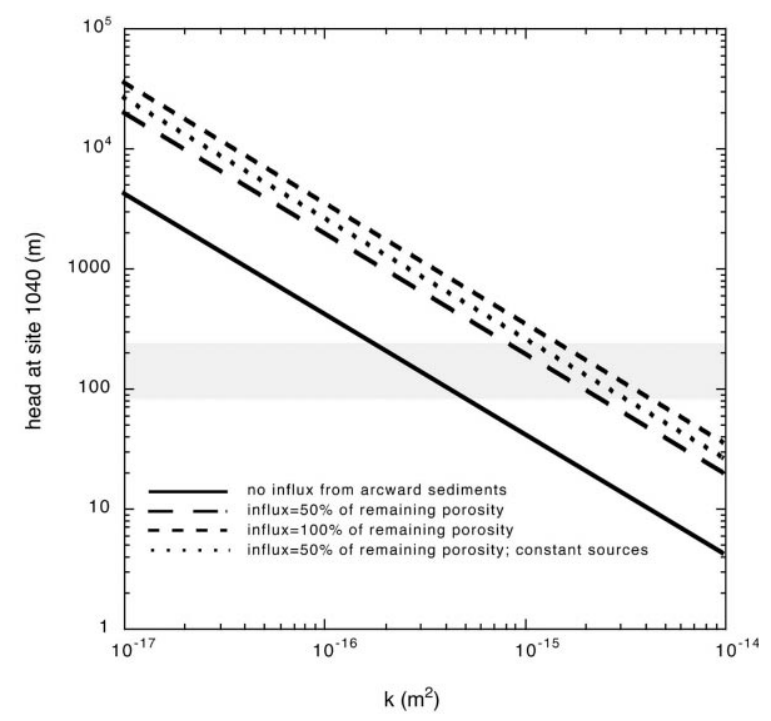

Fig. 8. Modeled head at site 1040 versus bulk permeability for constant permeability models. Solid lines are model results for variable source distribution (gray line in Fig. 7B). Solid, long-dashed, and short-dashed lines represent model output for influxes of 0,50 and $100 \%$ of remaining pore water, respectively. Dotted line shows model output for an influx equal to $50 \%$ of remaining porosity, using constant fluid sources (dotted line in Fig. 7B). Gray shaded area denotes range of head values inferred from consolidation tests. Sediment bulk permeabilities ranging from $2 \times 10^{-16}$ to $4.5 \times 10^{-15} \mathrm{~m}^{2}$ are consistent with inferred pore pressures. meability required to match inferred pore pressures at Site 1040 ranges from $2 \times 10^{-16}$ to $4.5 \times 10^{-15} \mathrm{~m}^{2}$ (Fig. 8). These permeability values are $\sim 100$ times higher than those measured for the hemipelagic section, but are comparable to measured permeabilities for the pelagic chalk (Fig. 6). This range of permeability values accounts for both the full range of pore pressures inferred from consolidation tests, and the range of fluid influx from deeper sediments as discussed above. A smaller influx of deeply sourced fluids can reproduce inferred pore pressures with a lower bulk permeability, whereas a larger influx requires higher permeability.

Using the constant source distribution shown in Fig. 7B, slightly higher permeability is required than for a source distribution based on loss of unit thickness (Fig. 8). The small difference between modeled pore pressures for variable and constant source distributions indicates that our results are insensitive to this uncertainty. Distributed dewatering elevates fluid sources far from the wedge toe, resulting in slightly higher modeled pore pressures at Site 1040 .

\subsection{Variable permeability model results}

Modeled pore pressures calculated for the case of variable permeability (Fig. 7C) increase rapidly with distance from the toe of the margin wedge (Fig. 9). Using permeabilities calculated from mean void ratio by Eq. 3, resulting head values at Site 1040 range from $7000-40000 \mathrm{~m}$. This range of values reflects a range of assumed fluid influxes at the arcward boundary, between 0 and $50 \%$ of remaining porosity. By comparison, head values inferred from consolidation tests are 80 $265 \mathrm{~m}$, with a most-likely average value of 180 m (Fig. 9). The upper limit, determined for undrained loading below the margin wedge, is $\sim 300 \pm 10 \mathrm{~m}$.

Using permeabilities 100 times those calculated by Eq. 3, modeled pore pressures at Site 1040 are consistent with the constraints discussed above (Fig. 9). Under these conditions, modeled pore pressures throughout the model domain are consistent with an inferred upper limit defined by undrained burial. With increased influx from 


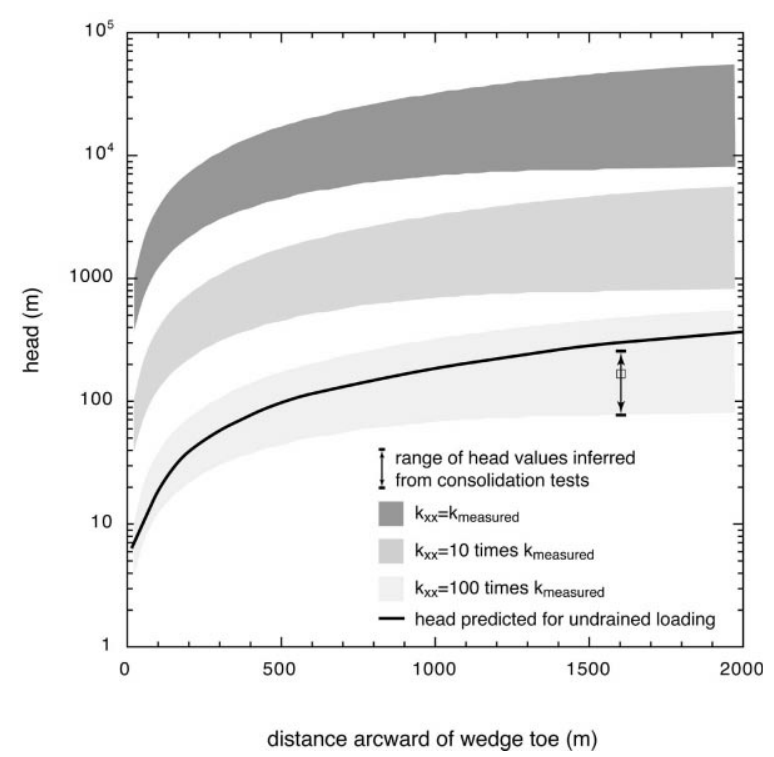

Fig. 9. Modeled head profiles from the trench to $2 \mathrm{~km}$ arcward, using variable permeability model for the hemipelagic section. Dark gray, medium gray, and light gray shaded areas denote the range of modeled head values for permeabilities of 1,10 and 100 times those calculated from mean void ratio by Eq. 3. The lower boundary of each shaded area represents zero fluid influx from deeper sediments, whereas the upper boundaries show model results for an influx equal to $50 \%$ of remaining porosity. Double-sided arrow shows the range of head values inferred from consolidation tests, and the open box denotes the average of most likely values determined by the Casagrande method and Eq. 1 . Black line denotes an upper limit for head values, equal to the excess pore pressure predicted for undrained loading below the margin wedge.

deeper sediments, higher permeabilities are required for agreement between modeled and inferred pore pressures. Again, permeability values which yield modeled pore pressures consistent with our constraints are comparable to the permeabilities measured in pelagic carbonate samples.

\subsection{Estimating the effects of vertical fluid loss}

Because some fluid may escape from the underthrust sediments by vertical flow, we estimate the effects of vertical fluid loss. We assume that fluids escaping the underthrust section in this manner flow upward to either the décollement or to a high-permeability conduit immediately below it, as discussed above. To represent vertical fluid escape in our one-dimensional model, we reduce the fluid sources and horizontal fluid flux through all model elements by a factor ranging from 0 to $99 \%$. For a given permeability, modeled head decreases with increasing fluid loss (Fig. 10). Head decreases appreciably only if vertical fluid loss approaches $50 \%$. With lateral permeabilities that are 10 times measured values, fluid losses of 70 $90 \%$ by vertical flow are required to match inferred pore pressures at Site 1040. With smaller fluid losses, bulk lateral permeabilities $\sim 100$ times measured values are required.

For comparison, we calculate upward flow

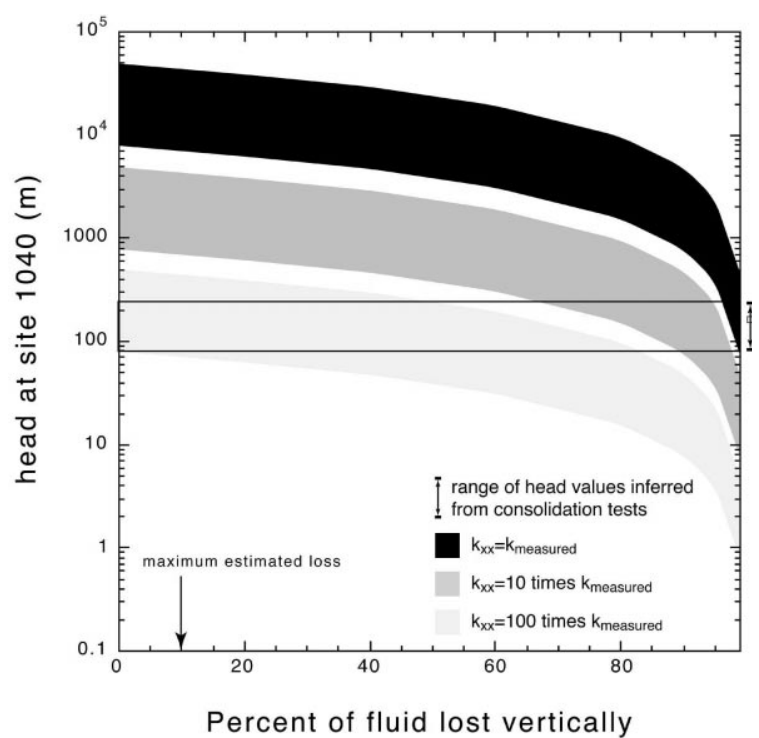

Fig. 10. Modeled head at Site 1040, plotted as a function of fluid lost to vertical dewatering. As in Fig. 9, dark gray, medium gray and light gray shaded areas denote the range of modeled head values for permeabilities of 1,10 and 100 times those calculated from mean void ratio by Eq. 3. The lower boundary of each shaded area represents zero fluid influx from deeper sediments, whereas the upper boundaries show model results for an influx equal to $50 \%$ of remaining porosity. Double-sided arrow shows the range of head values inferred from consolidation tests, and the open box denotes the average of most likely values determined by the Casagrande method and Eq. 1. For a given permeability, modeled head decreases with increasing fluid loss. Head decreases appreciably only once vertical fluid loss approaches $50 \%$. Our estimate for the maximum loss of fluid by diffuse vertical dewatering is $9 \%$ (see discussion in text). 
rates using vertical permeabilities calculated from Eq. 3. We define a head gradient using the maximum inferred pore pressure at the base of the hemipelagic section (Fig. 5), and assuming that the drainage interface at the top of the underthrust is at hydrostatic pressure. Upward flux is given by:

$Q=\left(\frac{\mathrm{d} h}{\mathrm{~d} z} \times \frac{1}{2}\right) \bar{K} x$

where $\bar{K}$ is the mean hydraulic conductivity in the model domain and $x$ is the lateral extent of the domain. We multiply $\mathrm{d} h / \mathrm{d} z$ by one-half to obtain a mean head gradient for the model domain, under the assumption that it varies linearly between zero at the toe of the wedge and the value calculated at $\sim 2 \mathrm{~km}$ arcward.

We calculate an upward flux of $\sim 0.49 \mathrm{~m}^{3} \mathrm{yr}^{-1}$ per meter of margin within the model domain. This represents $\sim 9 \%$ of fluid sources in the hemipelagic section. We consider this percentage a maximum, for several reasons. First, it is unlikely that the horizontal drainage interface is at hydrostatic fluid pressure, particularly if high-permeability there is maintained by dilation or arrested compaction (e.g. [27,28]). Second, vertical hydraulic conductivity is limited by low-permeability layers. Using a mean permeability within the hemipelagic section is adequate to approximate bulk horizontal hydraulic conductivity, but does not account for the effect of low-permeability layers on bulk vertical conductivity. Such low-permeability layers may result from either compaction or lithologic variation. Third, the fluids lost by upward flow are partially derived from the pelagic section below, yet we calculate fluid loss as a percentage of sources in the hemipelagic section only. Microfaults associated with deformation in the underthrust section may act as conduits for vertical fluid escape, but in order to effectively drain the sediments such structures would have to be continuous and closely spaced. With widely spaced conduits, access to fluids is limited by the sediment bulk permeability.

\section{Discussion}

Fluid escape from the hemipelagic underthrust sediments, documented by unit thinning, cannot be explained by lateral drainage through the sediment column unless bulk permeability is $\sim 100$ times that derived from laboratory measurements, or unless $>70 \%$ of fluids are lost by upward flow. We conclude that dewatering of the hemipelagic sediments may occur by (1) bedding-parallel flow within highly anisotropic sediments, (2) lateral flow within high permeability stratigraphic conduits or (3) extensive upward flow focused in
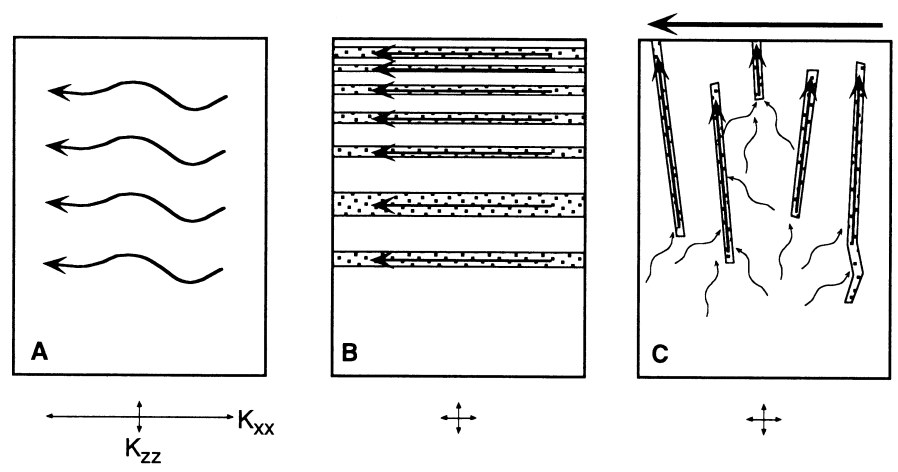

Fig. 11. Schematic diagram of dewatering pathways consistent with our results. Permeability tensors depicted here are for the sediment matrix and are not to scale. (A) Highly anisotropic permeability can allow lateral dewatering if horizontal permeability is $\sim 100$ times measured vertical permeability. (B) Distributed high-permeability stratigraphic layers $\left(k=10^{-14}\right.$ to $\left.10^{-15} \mathrm{~m}^{2}\right)$ are consistent with lateral dewatering. Such layers must occur throughout the hemipelagic section in order to access fluids. (C) Vertical dewatering through fractures may increase the vertical fluid loss and thus allow expulsion of fluids. Localized vertical flow requires closely spaced high-permeability conduits in order to access fluids. 
high permeability fissures, followed by lateral flow out along the décollement or a conduit within disrupted bedding just below the décollement (Fig. 11A-C).

The first scenario (Fig. 11A), implies that laboratory measurements of vertical hydraulic conductivity are significantly lower than actual horizontal hydraulic conductivity. If sediment permeability is anisotropic by a factor of $\sim 100$, lateral flow is consistent with estimated pore pressures.

Alternatively, if laboratory measurements of vertical permeability accurately represent horizontal permeabilities, then focused flow is required (Fig. 11B). In the case of focused flow along high permeability stratigraphic conduits, the total thickness of high permeability layers required for dewatering scales with the permeability of the conduits. At the toe of the wedge, conduits with a permeability of $10^{-14} \mathrm{~m}^{2}$ and a summed thickness of 3.8-9.5 m are needed, assuming no influx of fluids from deeper underthrust sediments. This range of thicknesses reflects the full range of inferred pore pressures within the hemipelagic section (Fig. 5). If influx at the arcward boundary is $50 \%$ of remaining porosity, conduits with summed thickness of 15-45 m are required. For a conduit permeability of $10^{-15} \mathrm{~m}^{2}$, required thicknesses increase by an order of magnitude. Rapid porosity loss should be observed adjacent to high permeability conduits; the fact that no such zones are documented down-hole implies that if drainage along permeable stratigraphic horizons is significant, these conduits must be distributed throughout the hemipelagic section. The coarse-grained ash layers observed in cores are candidates for focusing lateral flow.

Based on laboratory measurements of vertical permeability, we calculate that the maximum volume of fluid lost by upward flow is $9 \%$ of the fluid sources in the hemipelagic section. Thus, reduction of lateral fluxes by $>70 \%$ would require that vertical flow occurs within high-permeability conduits. Dewatering by upward flow along fissures to a subhorizontal drainage interface (Fig. 11C) is consistent with the lack of evidence for vertical flow from down-hole geochemical and thermal profiles, because such upward flow would be confined to local conduits that may not have been sampled by drilling. We conclude that upward dewatering through fractures may be great enough to accommodate known fluid sources from compaction. However, localized vertical flow requires closely spaced high-permeability conduits in order to access fluids from surrounding sediments, and few such structures are documented by drilling. It is possible that dewatering occurs through a combination of focused vertical fluid flow along structural conduits, and horizontal flow along high-permeability layers.

In comparison, permeabilities measured for pelagic carbonates are $\sim 100$ times those for the hemipelagic sediments; dewatering of these sediments by lateral flow is thus consistent with measured permeabilities. If the effective permeability within the pelagic sediments is isotropic $\left(k_{x x}=k_{z z}\right)$ then measured vertical permeabilities at the core scale are compatible with the permeabilities required to accommodate the known fluid sources from compaction and also match inferred pore pressures. This interpretation is also consistent with the lithostratigraphic observation that potentially high-permeability, coarse-grained ash layers are rare in the pelagic carbonates (e.g. [7]).

\section{Summary and conclusions}

Laboratory consolidation and permeability test results, when combined with down-hole observations from ODP Leg 170, provide insight into dewatering processes in the shallow subduction zone offshore Costa Rica. In situ excess pore pressures inferred from consolidation tests illustrate that the entire underthrust sedimentary section remains highly overpressured to at least $1.6 \mathrm{~km}$ landward from the onset of tectonic burial. At the present convergence rate, this corresponds to $\sim 19$ kyr. Excess fluid pressures of 1.3-3.1 MPa systematically decrease upsection. In comparison, the expected excess fluid pressure for undrained loading beneath the present wedge is $3.0 \pm 0.1$ $\mathrm{MPa}$.

Increasing excess fluid pressures with depth, along with observed changes in void ratio and bulk density, imply that fluids escape from the 
shallowest sediments more rapidly than from deeper sediments. Furthermore, the inferred pore pressure profile suggests that the volcanic ocean crust does not play a major role in the escape of overpressured fluids, despite vigorous lateral flow within the crust required to explain low regional heat flow. Our results imply that the sediment and volcanic crustal hydrologic systems are decoupled.

We incorporate permeability measurements into a one-dimensional steady-state flow model to evaluate potential dewatering scenarios. In order to maintain fluid pressures consistent with those inferred from consolidation tests and also allow the water loss documented by thinning of sedimentary units, we find that permeabilities for the hemipelagic section must be $\sim 100$ times those measured in samples, whereas model results are consistent with permeability data from the pelagic section. This result implies some combination of the following: (1) hemipelagic sediment permeability is strongly anisotropic, (2) fluid escape occurs within permeable stratigraphic conduits or (3) a significant fraction of fluids flow upward within localized conduits, and subsequently escape along a subhorizontal path near the top of the section. In light of this, future studies of fluid flow and dewatering at convergent margins should attempt to incorporate both vertical and lateral (or bedding-parallel) measurements of permeability.

\section{Acknowledgements}

Demian Saffer was supported for this work by NSF grant DGE-9616038 and by JOI/USSSP grant 170-F000511. Computing facilities were supported by NSF grant OCE9618166. Laboratory equipment at UCSC was supported by NSF OCE 98-19242 and CULAR grant 98-202 to Andrew Fisher. We would like to thank Julie Morris, Alex Maltman, and Bernie Housen for careful reviews and constructive criticism. We also thank Barbara A. Bekins and J. Casey Moore for helpful comments. Emily Giambalvo (UCSC) and Kate Jarrett (Bedford Institute of Oceanography) provided valuable technical support for laboratory tests.[CL]

\section{References}

[1] M.K. Hubbert, W.W. Rubey, Role of fluid pressure in mechanics of overthrust faulting, Geol. Soc. Am. Bull. 70 (1959) 115-166.

[2] D.M. Davis, J. Suppe, F.A. Dahlen, Mechanics of fold and thrust belts and accretionary wedges, J. Geophys. Res. 88 (1983) 949-963.

[3] D.E. Byrne, D.M. Davis, L.R. Sykes, Loci and maximum size of thrust earthquakes and the mechanics of the shallow region of subduction zones, Tectonics 7 (1988) 833 857.

[4] S. Bilek, T. Lay, Variation of interplate fault zone properties with depth in the Japan subduction zone, Science 281 (1998) 1175-1178.

[5] T. Plank, C.H. Langmuir, Tracing trace elements from sediment input to volcanic output at subduction zones, Nature 362 (1993) 739-743.

[6] S. Lallemand, High rates of arc consumption by subduction processes: some consequences, Geology 23 (1995) 551-554.

[7] G. Kimura, E. Silver, P. Blum et al., Proc. ODP, Init. Reports 170, Texas A\&M University, Ocean Drilling Program, College Station, TX, 1997.

[8] T.H. Shipley, K.D. McIntosh, E.A. Silver, P.L. Stoffa, Three-dimensional seismic imaging of the Costa Rica accretionary prism; structural diversity in a small volume of the lower slope, J. Geophys. Res. 97 (1992) 4439-4459.

[9] S. Ye, J. Bialas, E.R. Flueh, A. Stavenhagen, R. von Huene, G. Leandro, K. Hinz, Crustal structure of the Middle American Trench off Costa Rica from wide-angle seismic data, Tectonics 15 (1996) 1006-1021.

[10] X. Le Pichon et al., Accretion and erosion in subduction zones: the role of fluids, Earth Planet. Sci. Lett. 21 (1993) 307-331.

[11] J. Aubouin, R. von Huene, Summary; Leg 84, Middle America Trench transect off Guatemala and Costa Rica, Proc. DSDP Init. Rep. 84 (1985) 939-957.

[12] W.T. Coulbourn, Stratigraphy and structures of the Middle America Trench; Deep Sea Drilling Project Leg 67 transect off Guatemala, Proc. DSDP Init. Rep. 67 (1982) 691-706.

[13] R.D. Holtz, W.D. Kovacs, An Introduction to Geotechnical Engineering, Prentice-Hall, Englewood Cliffs, NJ, 1981.

[14] J.C. Moore, Tectonics and hydrogeology of accretionary prisms: role of the décollement zone, J. Struct. Geol. 11 (1989) 95-106.

[15] J.H. Behrmann, A. Kopf, Textures and microfabrics in fine-grained muds and mudstones from site 808, Nankai accretionary prism, Proc. ODP Sci. Results 131 (1993) 45 55.

[16] D.M. Saffer et al., Consolidation, pore fluid pressures, and implications for dewatering pathways of subducted sediments, offshore Costa Rica, Eos (Trans.) Am. Geophys. Union 78 (1997) 685.

[17] B.A. Housen et al., Strain decoupling across the décolle- 
ment of the Barbados accretionary prism, Geology 24 (1996) 127-130.

[18] J.K. Morgan, D.E. Karig, Ductile strains in clay-rich sediments from Hole $808 \mathrm{C}$; preliminary results using X-ray pole figure goniometry, Proc. ODP Sci. Results 131 (1993) 141-155.

[19] C.E. Neuzil, How permeable are clays and shales?, Water Res. 30 (1994) 145-150.

[20] A. Bolton, M.B. Clennell, A.J. Maltman, Nonlinear stress dependence of permeability: a mechanism for episodic fluid flow in accretionary wedges, Geology 27 (1999) 239-242.

[21] W.R. Bryant et al., Permeability of unconsolidated marine sediments, Gulf of Mexico, Mar. Geotech. 1 (1975) 1-14.

[22] H. Tobin, P. Vannucchi, M. Meschede, S. Saito, ODP Leg 170 Scientific Party, Structure and inferred mechanical propoerties of the décollement zone, Costa Rica convergent margin, Eos (Trans.) Am. Geophys. Union 78 (1997) 707.
[23] V. Vacquier, Studies of the thermal state of the Earth; Part 21, Heat-flow, eastern Pacific, Bull. Earthq. Res. Inst. Univ. Tokyo 45 (1967) 375-393.

[24] M. Kastner et al., Hydrogeology and composition of fluids at the Costa Rica subduction zone; new results and Mark's contribution, Eos (Trans.) Am. Geophys. Union 78 (1997) 672.

[25] A.T. Fisher, Permeability within basaltic oceanic crust, Rev. Geophys. 36 (1998) 143-182.

[26] K. McIntosh et al., Evidence and mechanisms for forearc extension at the accretionary Costa Rica convergent margin, Tectonics 12 (1993) 1380-1392.

[27] A.T. Fisher, G. Zwart, Relation between permeability and effective stress along a plate-boundary fault, Barbados accretionary complex, Geology 24 (1996) 307-310.

[28] J.C. Moore et al., Consolidation patterns during initiation and evolution of a plate boundary décollement zone Northern Barbados accretionary prism, Geology 26 (1998) 811-814. 